\title{
High visceral adiposity index associated with metabolic syndrome impairs erectile function in sexually active men.
}

\author{
Mustafa Bolat ${ }^{1}$, Mustafa Latif Özbek ${ }^{2}$, Bekir Şahin ${ }^{3}$, Merve YILMAZ ${ }^{3}$, Fatih \\ Kocamanoğlu ${ }^{4}$, Recep Büyükalpelli ${ }^{5}$, Ahmet Tevfik Sunter ${ }^{6}$, and Ramazan Aşçı ${ }^{5}$ \\ ${ }^{1}$ Samsun Gazi State Hospital \\ ${ }^{2}$ Private Atasam Hospital \\ ${ }^{3}$ Gazi State Hospital \\ ${ }^{4}$ City Hospital \\ ${ }^{5}$ Ondokuz Mayis University Faculty of Medicine \\ ${ }^{6}$ Ondokuz Mayis University, School of Medicine,
}

December 11, 2020

\begin{abstract}
Aims:Erectile dysfunction (ED) is a common condition affected by many factors. We aimed to show the impact of the metabolic syndrome (MeTS) on male sexual function based on VAI and the impact of increased levels of the VAI was investigated in patients with ED among the patients with and without MeTS. Methods:Participants who met MeTS criteria (Group 1, n=96) and without MeTS (Group 2, $\mathrm{n}=189$ ) were included in this cross-sectional study. The MeTS diagnosis was made in the presence of at least three of the following criteria: serum glucose level higher than $100 \mathrm{mg} / \mathrm{dl}$, HDL cholesterol level below $40 \mathrm{mg} / \mathrm{dl}$, triglyceride level greater than $150 \mathrm{mg} / \mathrm{dl}$, waist circumference greater than $102 \mathrm{~cm}$ and blood pressure greater than $130 / 85$ $\mathrm{mmHg}$. Demographic data were recorded; biochemical and hormonal tests were measured. Erectile and other sexual function scores were recorded. The VAI was calculated using the $[(\mathrm{WC} / 39.68)+(1.88 \mathrm{xMI})] \mathrm{xTG} / 1.03 \mathrm{x} 1.31 / \mathrm{HDL}$ formula. Results:Mean age, smoking volume, $\mathrm{T}$ and $\mathrm{T} / \mathrm{E} 2$ ratios of the groups were similar $(\mathrm{p}>0.05)$. Mean VAI was two-fold higher in patients in Group $1(\mathrm{p}<0.001)$ and erectile function score was lower in Group 1 than Group $2(\mathrm{p}=0.001)$. Other sexual function scores were similar $(\mathrm{p}>0.05)$. The METS was associated with an increased risk of ED $(\mathrm{p}=0.001)$. Logistic regression analysis showed that each integer increase of the VAI was associated with a 1.4-fold increased risk of ED $(\mathrm{p}<0.001)$. Higher T values were associated with a better erectile function $(\mathrm{p}=0.03)$. For the $\mathrm{VAI}=4.33$, receiver-operating characteristic analysis showed a sensitivity of $89.6 \%$ and specificity of $57.7 \%$. Conclusion:Compared to non-MeTS, the presence of MeTS has emerged as a risk factor for patients with ED with high VAI levels while the other sexual functions are preserved. Management of ED patients with MeTS should cover a comprehensive metabolic and endocrinological evaluation in addition to andrological work up.
\end{abstract}

\section{Introduction}

In men, sexual function is provided by the central and peripheral nervous system's harmonious work together with hormonal mechanisms and vascular systems. The sexual function covers the erectile, orgasmic, desire, ejaculatory components in addition to sexual and general satisfaction. Although erectile dysfunction (ED) is managed as a sexual problem, it can be a messenger of impending significant circumstances such as coronary artery disease [1]. Some modifiable and nonmodifiable risk factors, including increasing age and metabolic syndrome (MeTS), may negatively affect sexual function [2,3]. The current opinion in medicine is to take preventive measures before the complications develop against diseases that can lead to lifelong comorbidities [4]. The MeTS, which is associated with many conditions, can also cause ED. For men, at least three of the modifiable criteria are sufficient for the diagnosis of MeTS (Table 1) [5]. 
Increased fat accumulation without the diagnosis of MeTS also causes sexual dysfunction in men by decreasing the quality of life and damaging the vascular endothelial mechanism via increased amounts of inflammatory products, including cytokines, adipokine, and fatty acids cause nitric oxide insufficiency [6]. Although cavernous arteries are slowly affected by the atherosclerotic process, early diagnosis of ED remains important before irreversible damage develops [7]. Due to the body mass index (BMI) and waist circumference (WC) cannot homogenously compute the fat distribution [8], a decade ago, the gender-specific visceral adiposity index (VAI) was first introduced by Amato et al. as an indicator of adipose tissue dysfunction, which combines HDL cholesterol, triglyceride, BMI and WC in a formula [9]. Based on the limited number of studies investigating the relationship between VAI and ED, we recently demonstrated a 1.3-fold increased risk of ED in response to each integer increase of VAI [10]. However, a debate is still open whether male sexual dysfunction could be recovered when the correctable risk factors are adequately managed and when the VAI level is decreased.

In this study, we aimed to show the impact of the MeTS on male sexual functions based on VAI. We also aimed to highlight the importance of seeking the urologists to receive comprehensive support from different disciplines and professional partners to manage life-long or correctable comorbidities that negatively affect erectile dysfunction.

\section{Materials and Methods}

After obtaining the Institutional Board approval of the XXX Local Ethics Committee, this prospective study was conducted among patients at outpatient urology clinics at four centers (A Hospital, B University, C Hospital and D City Hospital). Written informed consent was obtained. After a power analysis, a total of 285 sexually active men with complete data from 298 participants were included in the study. Patients with incomplete data $(\mathrm{n}=3)$, active neurological disorders $(\mathrm{n}=4)$, unwilling to participate $(\mathrm{n}=1)$, end-stage renal failure $(\mathrm{n}=1)$, those with a history of total thyroidectomy $(\mathrm{n}=2)$ and patients with urogenital cancer surgery $(n=2)$ were excluded from the study. Patients with sexual dysfunction who met or did not meet the MeTS criteria, those who applied to the urology clinic with complaints of sexual dysfunction and those who were referred from Internal Medicine and Endocrinology clinics were included in the study. Participants were given the Turkish-validated 15-items long-form of the International Index of Erectile Dysfunction (IIEF) questionnaire to fill under a urologist's supervision. Erectile function was assessed using the IIEF 1-5 and 15th items; sexual satisfaction, orgasmic function, sexual desire and general satisfaction were assessed using the IIEF 6-8th, 9-10th, 11-12th 13-14th items, respectively. Participants with IIEF 1-5 and 15 scores [?]26 were defined as non-ED patients, those with IIEF $1-5$ and 15 score $=22-25$ were mild ED, IIEF $1-5$ and 15 scores $=17-21$ were mild-to-moderate ED, IIEF $1-5$ and 15 scores $=11-16$ were moderate ED, and IIEF 1-5 and 15 scores $=0-10$ were defined as severe ED. The BMI was calculated using the $\mathrm{kg} / \mathrm{m} 2$ formula. Waist circumference measurement was performed at the level of the umbilicus. The mean age of the patients and comorbidities, including hypertension and diabetes mellitus, medications, smoking and alcohol habits, and ED duration, were recorded. The VAI was calculated using $[(\mathrm{WC} / 39.68)+(1.88 \times \mathrm{BMI})] \mathrm{x}$ TG / $1.03 \times 1.31$ / HDL male sex-specific formula [9]. The mean sexual satisfaction, orgasm, desire and general satisfaction scores were calculated. Among the participants, 96 patients with MeTS criteria were defined as Group 1 and 189 with no MeTS criteria were defined as Group 2. Using the enzyme-linked immunosorbent assay (ELISA), single hormonal analysis for total testosterone (T), prolactin (PRL), estradiol (E2) tests were performed from morning fasting venous blood samples when needed. Aromatase activity was calculated using the T/E2 formula where available [11]. The mean VAI, erectile function score, sexual satisfaction, orgasm, desire and overall satisfaction scores were statistically compared between the groups.

Statistical Analysis

The Statistical Package for the Social Sciences (version 21.0.; IBM, Armonk, NY) was used to evaluate the data. The results were given as mean \pm standard deviation for normally distributed data and frequencies (percentages) for categorical variables. Student-t, Mann-Whitney U test was used to assess the differences between the groups. Multivariate logistic regression analysis was performed to determine the VAI's impact and the MeTS on sexual function. A p-value smaller than 0.05 was accepted as statistically significant. 


\section{Results}

Mean age, smoking volume, $\mathrm{T}$ and $\mathrm{T} / \mathrm{E} 2$ ratios of the groups were similar ( $\mathrm{p}>0.05)$. The mean BMI and WC were significantly higher in Group 1 than Group $2(\mathrm{p}<0.05)$. Proportions of obesity and morbid obesity were much higher in Group 1 than Group 2. The majority of Group 1 patients had at least four or five MeTS criteria $(50 \%+11.5)$ (Table 2). The majority of Group 2 patients had one or two criteria of MeTS $(37.6 \%+43.9 \%)$. Mean VAI was two-fold higher in patients in Group 1 than Group 2 ( $p<0.001)$. Mean sexual satisfaction, desire, orgasm, and general satisfaction rates were similar between groups $(\mathrm{p}>0.05)$. Group 1 had higher diabetes, hypertension and coronary artery disease rates than Group $2(\mathrm{p}=0.001)$. The mean erectile function score was $13.6 \pm 7.7$ in Group 1 compared to $18.8 \pm 7.9$ in Group 2 ( $\mathrm{p}=0.001$ ). Severe and moderate ED scores were observed in $61.5 \%$ of the cases in Group 1, while this rate was $39.1 \%$ in Group 2. (Table 2). Multivariate logistic regression analysis showed that the VAI was associated with a 1.4-fold increased risk of ED ( $\mathrm{p}<0.01, \mathrm{OR}=1.4$ (95\% CI 1.4-1.7) and higher T values were associated with a better erectile function $(\mathrm{p}=0.03, \mathrm{OR}=0.7,95 \%$ CI $0.5-1)$. Regarding the VAI, the receiver-operating characteristic (ROC) analysis showed for the $\mathrm{VAI}=4.33$ value, the area under the curve (AUC) was 0.835 (95\% CI: $0.786-0.884)$ with a sensitivity of $89.6 \%$ and specificity of $57.7 \%$ (Figure 1).

\section{Discussion}

According to the American Association of Clinical Endocrinologists Medical Guidelines for Clinical Practice, the prevalence of obesity increased sharply. It continues to be a global problem over the past three decades. Not only adults but also children and adolescents are at risk of overweight or obesity [12]. To date, many reports have been published showing the association between MetS and cardiovascular diseases and ED and cardiovascular diseases. Still, only several analyses showed the associations between ED and MeTS. The common feature of the coronary and genital arteries' destructive process is that these arteries have similar structures and are easily affected by risk factors such as MeTS. Cavernosal arteries tend to be involved at first glance due to their smaller diameters than coronary counterparts, and the presence of MeTS often worsens the ED [1]. The presence of the MeTS has been linked with a two-fold increased risk of ten years of cardiovascular events [13]. Liu et al. sought whether MetS was an independent risk factor for ED or just a silent marker of ED, and they showed in a meta-analytical study that MeTS significantly increased the risk for ED [14]. Smoking causes a decrease in endothelial elasticity over time through a direct toxic effect on the endothelium. [15]. Previous reports have reported that smoking has a dose-dependent impact on ED, and more than 20 years/pack smoking accelerates the ED process. In our study, smoking volumes were less than 20 packs/year for groups [16]. This finding could explain that the ED progressed similarly. However, in particular populations such as in patients with MeTS, it would not be misleading to think that a lower smoking volume could accelerate the ED process where complex risk factors coexistent. Smoking is an independent but preventable risk factor. Creamer et al. reported that three out of five smokers succeed in quitting in 2018 [17].

MeTS may predispose to ED by decreasing the circulating androgen level [18]. High blood lipid profile and high systolic blood pressure are associated with a decrease in endothelial elasticity [19], increased amounts of cytokines, adipokines, and fatty acids and their interactions with the endothelium cause decreased nitric oxide release, and subsequently, ED manifests. Increased cytokines, adipokines, fatty acids and their interactions with the endothelium cause decreased nitric oxide release, and later, ED embodies [6]. Patients with MeTS prone to have moderate to severe ED than those without MeTS [20]. The complexity of pathophysiological changes could be a challenging factor in patients with MeTS. In patients with MeTS, we observed a proportional increase in the severity of ED as the number of MeTS components increased. Indeed, in Group 1, the sum of severe and moderate ED rate was significantly higher than Group 2 (61.5\% vs 39.1\%). Although the decrease of total testosterone was similar in groups, the conversion of some circulating androgen levels upon the peripheric aromatase activity may accelerate the ED process [21].

Several reports have shown that mean VAI levels tend to rise in ED patients compared to non-ED patients [22,23]. Some authors have also reported an increase of VAI from different disciplines [24]. Our previous study showed that VAI increased in men with moderate and severe ED might be a reliable, independent 
risk factor for ED, especially at values above 4.33. We also concluded that researchers could use the VAI for monitoring the ED before it manifests or clinically manifested at a very early stage. However, as far as we know, the present study is the first to show that the mean VAI level in the MeTS arm increased by at least twice, reached $9.3 \pm 4.4$. A significant increase of the VAI is suspected to increase ED upon several complex pathways. A decrease of endothelial nitric oxide release, low T / E2 secondary to circulating peripheral aromatase activity, increased circulating leptin, and diminished self-esteem may cause a potential increase in MeTS [10]. Still, any combination of multiple risk factors, including MeTS, could incredibly likely accelerate ED severity. As far as we know, this study is the first to show that the VAI level doubled in patients with MeTS. Our opinion is that researchers should take into account the rapid increase of the VAI in patients with MeTS. Contrary to previous reports, high VAI levels in patients with MeTS may challenge ED management. Therefore, management of such cases should cover a comprehensive metabolic and endocrinological evaluation in addition to andrological work up.

Contrary to current reports, some studies conflicting results that MeTS was not associated with an increased risk of ED. In one of them, the authors stated no difference in the prevalence of ED between men with or without MetS but, age, presence of depressive symptoms and lower education were significant predictors of ED [25]. Plata et al. also reported no relationship between MetS and ED among urological patients, probably due to the low prevalence of MetS [26]. The methodological settings of these studies due to the low number of MeTS patients might have been insufficient to explain the relationship between MeTS and ED.

Strengths \& Limitations: This study's main strength is the first to investigate very high VAI levels in men with ED in a specific risk group such as METS. Lack of assessment of the penile vascular system using penile duplex ultrasonography, lack of measurement of cytotoxic end-products that may interfere with endothelial function and only a single testosterone measurement using the enzyme-linked immunosorbent assay are the limiting factors.

\section{Conclusions}

The increased combination of multiple risk factors in patients with MeTS can dramatically accelerate ED severity with doubling VAI levels. Our findings suggested that investigators should consider the rapid increase in VAI in patients with MeTS, which may challenge ED management, and the management of such cases should include a comprehensive metabolic and endocrinological evaluation in addition to andrological examination.

\section{References}

1. Gandaglia G, Briganti A, Jackson G, Kloner RA, Montorsi F, Montorsi P, Vlachopoulos C. A systematic review of the association between erectile dysfunction and cardiovascular disease. Eur Urol. 2014 May;65(5):968-78. doi: 10.1016/j.eururo.2013.08.023. Epub 2013 Aug 23. PMID: 24011423.

2. Hatzimouratidis K, Giuliano F, Moncada I, et al. European Association of Urology (EAU). Guideline on male sexual dysfunction. 2017 Edition.

3. Mulhall J, Teloken P, Brock G, Kim E. Obesity, dyslipidemias and erectile dysfunction: a report of a subcommittee of the sexual medicine society of North America. J Sex Med. 2006 Sep;3(5):778-786. doi: 10.1111/j.1743-6109.2006.00286.x. PMID: 16942522.

4. Johnson EP, Dunn M, Cooper M, Bhakta N. Diabetes Prevention Program Sites Compared With Diabetes Prevalence and Ratio of Primary Care Physicians in Texas. Prev Chronic Dis. 2019 Dec 26;16:E165. doi: 10.5888/pcd16.190175. PMID: 31878987; PMCID: PMC6936669.

5. Watanabe K, Cho YD. Periodontal disease and metabolic syndrome: a qualitative critical review of their association. Arch Oral Biol. 2014 Aug;59(8):855-70. doi: 10.1016/j.archoralbio.2014.05.003. Epub 2014 May 14. PMID: 24880501; PMCID: PMC4399819.

6. Goh VH, Hart WG. Association of general and abdominal obesity with age, endocrine and metabolic factors in Asian men. Aging Male. 2016;19(1):27-33. doi: 10.3109/13685538.2015.1088825. Epub 2015 Oct 7. PMID: 26444311.

7. Feldman HA, Goldstein I, Hatzichristou DG, Krane RJ, McKinlay JB. Impotence and its medical and 
psychosocial correlates: results of the Massachusetts Male Aging Study. J Urol. 1994 Jan;151(1):54-61. doi: 10.1016/s0022-5347(17)34871-1. PMID: 8254833.

8. Romero-Corral A, Montori VM, Somers VK, Korinek J, Thomas RJ, Allison TG, Mookadam F, LopezJimenez F. Association of bodyweight with total mortality and with cardiovascular events in coronary artery disease: a systematic review of cohort studies. Lancet. 2006 Aug 19;368(9536):666-78. doi: 10.1016/S0140-6736(06)69251-9. PMID: 16920472.

9. Amato MC, Giordano C, Galia M, Criscimanna A, Vitabile S, Midiri M, Galluzzo A; AlkaMeSy Study Group. Visceral Adiposity Index: a reliable indicator of visceral fat function associated with cardiometabolic risk. Diabetes Care. 2010 Apr;33(4):920-2. doi: 10.2337/dc09-1825. Epub 2010 Jan 12. PMID: 20067971; PMCID: PMC2845052.

10. Bolat MS, Kocamanoglu F, Ozbek ML, Buyukalpelli R, Asci R. Can High Visceral Adiposity Index Be a Risk Factor for Sexual Dysfunction in Sexually Active Men? J Sex Med. 2020 Oct;17(10):1926-1933. doi: 10.1016/j.jsxm.2020.06.014. Epub 2020 Jul 23. PMID: 32712095.

11. Raman JD, Schlegel PN. Aromatase inhibitors for male infertility. J Urol. 2002 Feb;167(2 Pt 1):624-9. doi: 10.1097/00005392-200202000-00038. PMID: 11792932.

12. Hermans MP, Ahn SA, Rousseau MF. Erectile dysfunction, microangiopathy and UKPDS risk in type 2 diabetes. Diabetes Metab. 2009 Dec;35(6):484-9. doi: 10.1016/j.diabet.2009.06.003. PMID: 19897395.

13. Alberti KG, Eckel RH, Grundy SM, Zimmet PZ, Cleeman JI, Donato KA, Fruchart JC, James WP, Loria CM, Smith SC Jr; International Diabetes Federation Task Force on Epidemiology and Prevention; Hational Heart, Lung, and Blood Institute; American Heart Association; World Heart Federation; International Atherosclerosis Society; International Association for the Study of Obesity. Harmonizing the metabolic syndrome: a joint interim statement of the International Diabetes Federation Task Force on Epidemiology and Prevention; National Heart, Lung, and Blood Institute; American Heart Association; World Heart Federation; International Atherosclerosis Society; and International Association for the Study of Obesity. Circulation. 2009 Oct 20;120(16):1640-5. doi: 10.1161/CIRCULATIONAHA.109.192644. Epub 2009 Oct 5. PMID: 19805654.

14. Liu LH, Zhang T, Zhang YR, Liu TS, Zhang HB, Chen FZ, He SH, Wei AY. Metabolic syndrome and risk for ED: a meta-analysis. Int J Impot Res. 2014 Sep-Oct;26(5):196-200. doi: 10.1038/ijir.2014.3. Epub 2014 Mar 6. PMID: 24599048.

15. Austoni E, Mirone V, Parazzini F, Fasolo CB, Turchi P, Pescatori ES, Ricci E, Gentile V; Andrology Prevention Week centres; Italian Society of Andrology. Smoking as a risk factor for erectile dysfunction: data from the Andrology Prevention Weeks 2001-2002 a study of the Italian Society of Andrology (s.I.a.). Eur Urol. 2005 Nov;48(5):810-7; discussion 817-8. doi: 10.1016/j.eururo.2005.03.005. Epub 2005 Mar 16. PMID: 16202509.

16. Kupelian V, Link CL, McKinlay JB. Association between smoking, passive smoking, and erectile dysfunction: results from the Boston Area Community Health (BACH) Survey. Eur Urol 2007;52:416-422.

17. Creamer MR, Wang TW, Babb S, Cullen KA, Day H, Willis G, Jamal A, Neff L. Tobacco Product Use and Cessation Indicators Among Adults - United States, 2018. MMWR Morb Mortal Wkly Rep. 2019 Nov 15;68(45):1013-1019. doi: 10.15585/mmwr.mm6845a2. PMID: 31725711; PMCID: PMC6855510.

18. Laaksonen DE, Niskanen L, Punnonen K, Nyyssönen K, Tuomainen TP, Salonen R, Rauramaa R, Salonen JT. Sex hormones, inflammation and the metabolic syndrome: a population-based study. Eur J Endocrinol. 2003 Dec;149(6):601-8. doi: 10.1530/eje.0.1490601. PMID: 14641004.

19. Li M, Ma Z, Zhang XL, Guo LQ, Yuan MZ. Significance of blood lipid parameters as effective markers for arteriogenic erectile dysfunction. Andrology. 2020 Sep;8(5):1086-1094. doi: 10.1111/andr.12776. Epub 2020 Mar 9. PMID: 32087037.

20. García-Cruz E, Leibar-Tamayo A, Romero J, Piqueras M, Luque P, Cardeñosa O, Alcaraz A. Metabolic syndrome in men with low testosterone levels: relationship with cardiovascular risk factors and comorbidities and with erectile dysfunction. J Sex Med. 2013 Oct;10(10):2529-38. doi: 10.1111/jsm.12265. Epub 2013 Jul 30. PMID: 23898860.

21. Hemsell DL, Grodin JM, Brenner PF, Siiteri PK, MacDonald PC. Plasma precursors of estrogen. II. Correlation of the extent of conversion of plasma androstenedione to estrone with age. J Clin Endocrinol 
Metab. 1974 Mar;38(3):476-9. doi: 10.1210/jcem-38-3-476. PMID: 4815174.

22. Dursun M, Besiroglu H, Cakir SS, Otunctemur A, Ozbek E. Increased visceral adiposity index associated with sexual dysfunction in men. Aging Male. 2018 Sep;21(3):187-192. doi: 10.1080/13685538.2017.1406468. Epub 2017 Nov 22. PMID: 29166824.

23. Akdemir AO, Karabakan M, Aktas BK, Bozkurt A, Ozgur EG, Akdogan N, Yarıs M. Visceral adiposity index is useful for evaluating obesity effect on erectile dysfunction. Andrologia. 2019 Jul;51(6):e13282. doi: 10.1111/and.13282. Epub 2019 Apr 2. PMID: 30938454.

24. Anık İlhan G, Yıldızhan B. Visceral adiposity indicators as predictors of metabolic syndrome in postmenopausal women. Turk J Obstet Gynecol. 2019 Sep;16(3):164-168.

25. Kuneinen S, Kaaja RJ, Vahlberg TJ, Korhonen PE. Metabolic syndrome is not associated with erectile dysfunction in apparently healthy men. Prim Care Diabetes. 2020 Oct;14(5):460-463.

26. Plata M, Caicedo JI, Trujillo CG, Mariño-Alvarez ÁM, Fernandez N, Gutierrez A, Godoy F, Cabrera M, Cataño-Cataño JG, Robledo D. Prevalence of metabolic syndrome and its association with lower urinary tract symptoms and sexual function. Actas Urol Esp. 2017 Oct;41(8):522-528.

Table 1. MeTS* criteria according to the National Cholesterol Education Program (NCEP ATP3, 2005).

A waist circumference of greater than $102 \mathrm{~cm}$ Triglyceride level higher than $150 \mathrm{mg} / \mathrm{dL}$, or receiving treatment for hypertri *MeTS, metabolic syndrome

Table 2. Demographic and clinical results of the groups.

\begin{tabular}{|c|c|c|c|}
\hline $\begin{array}{l}\text { Variable (mean } \pm \\
\text { standard deviation) }\end{array}$ & $\begin{array}{l}\text { Group } 1 \text { Patients with } \\
\text { MeTS* }(\mathrm{n}=96)\end{array}$ & $\begin{array}{l}\text { Group } 2 \text { Patients with } \\
\text { no MeTS }(n=189)\end{array}$ & $\mathbf{p}$ \\
\hline Age (years) & $54.1 \pm 8.5$ & $53.1 \pm 8.4$ & 0.334 \\
\hline $\begin{array}{l}\text { Smoking volume } \\
\text { (pack/year) }\end{array}$ & $16.6 \pm 20.5$ & $13.4 \pm 16.5$ & 0.158 \\
\hline $\begin{array}{l}\mathrm{BMI}\left(\mathrm{Kg} / \mathrm{m}^{2}\right)^{* * *} \\
\text { Waist circumference } \\
(\mathrm{cm}) \text { Patients } \\
\text { according to BMI (n, } \\
\text { \%) Normal }([?] 24.9) \\
\text { Overweight } \\
(25.00-29.9) \text { Obese } \\
(30.0-39.9) \text { Morbid } \\
\text { obese ([?]40.0) }\end{array}$ & $\begin{array}{l}30.7 \pm 4.2110 .6 \pm 19.37 \\
(7.3) 37(38.5) 46 \\
(47.9) 6(6.3)\end{array}$ & $\begin{array}{l}27.4 \pm 4.099 .8 \pm 10.443 \\
(22.8) 108(57.1) 37 \\
(19.6) 1(0.5)\end{array}$ & 0.0010 .001 \\
\hline $\begin{array}{l}\text { Presence of MeTS with } \\
\text { None o the components } \\
\text { Only a component Two } \\
\text { components Three } \\
\text { components } 4^{\text {th }} \\
\text { component } 5^{\text {th }} \\
\text { component }\end{array}$ & $\begin{array}{l}--37(38.5) 48 \text { (50.0) } \\
11(11.5)\end{array}$ & $\begin{array}{l}35(18.5) 71(37.6) 83 \\
(43.9)---\end{array}$ & - \\
\hline $\begin{array}{l}\text { Comorbidity (n, \%) } \\
\text { Diabetes Mellitus } \\
\text { Hypertension Coronary } \\
\text { artery disease }\end{array}$ & $\begin{array}{l}26(27.1) 32(33.3) 16 \\
(16.7)\end{array}$ & $8(4.2) 11(5.8) 7(3.7)$ & $\begin{array}{lll}0.001 & 0.001 & 0.001\end{array}$ \\
\hline $\begin{array}{l}\text { Serum Testosterone } \\
(\mathrm{ng} / \mathrm{mL})\end{array}$ & $3.9 \pm 4.4$ & $4.1 \pm 1.6$ & 0.158 \\
\hline $\mathrm{T} / \mathrm{E}_{2}$ ratio $^{\#}$ & $0.18 \pm 0.19$ & $0.21 \pm 0.21$ & 0.361 \\
\hline $\mathrm{VAI}^{* *}$ & $9.3 \pm 4.4$ & $4.6 \pm 2.9$ & 0.001 \\
\hline
\end{tabular}


IIEF score ${ }^{\&}$ Patients according to Erectile function (n, \%) Severe (IIEF score $=0$-10)

Moderate (IIEF score

$=11-16$ )

Mild-to-moderate

(IIEF score $=17-21$ )

Mild (IIEF score =

22-25) No-erectile

dysfunction

Sexual satisfaction

Orgasm

Desire

General satisfaction

*MeTS, metabolic syndrome; **VAI, visceral adiposity index; ***BMI, body mass index; \# $\mathbf{T} / \mathbf{E}_{\mathbf{2}}$, testosterone to estradiol ratio;

${ }^{\&}$ IIEF, International Index of Erectile Function.
$13.6 \pm 7.733$ (34.4) 26

(27.1) 23 (23.9) 10

(10.4) 4 (4.2)

$18.8 \pm 7.934(17.9) 40$

(21.2) 34 (17.9) 42

(22.2) 39 (20.6)

\section{$7.4 \pm 4.3$ \\ $6.2 \pm 3.5$ \\ $6.3 \pm 2.7$ \\ $5.6 \pm 2.7$}

*MeTS, metabolic syndrome; **VAI, visceral adiposity index; ***BMI, body mass index; $\# \mathbf{T} / \mathbf{E}_{\mathbf{2}}$, testosterone to estradiol ratio; \&IIEF, International Index of Erectile Function.

\section{$7.1 \pm 4.2 \quad 0.568$ \\ $6.2 \pm 3.4 \quad 0.872$ \\ $5.7 \pm 2.7 \quad 0.468$ \\ $5.7 \pm 2.7 \quad 0.925$}

*MeTS, metabolic *MeTS, metabolic syndrome; **VAI, syndrome; **VAI, visceral adiposity visceral adiposity index; ***BMI, index; $* * * \mathrm{BMI}$, body mass index; body mass index; $\# \mathbf{T} / \mathbf{E}_{\mathbf{2}}$,

testosterone to estradiol ratio;

${ }^{\&}$ IIEF, International Index of Erectile Function.
${ }^{\#} \mathbf{T} / \mathbf{E}_{\mathbf{2}}$,

testosterone to estradiol ratio;

\& IIEF, International Index of Erectile Function.

Figure Legend

Fig. 1. Receiver operator characteristics (ROC) curve for visceral adiposity index for VAI=4.33, Sensitivity $=89.6 \%$, Specificity $=57.7 \%$.

\section{Hosted file}

Figure 1. ROC.pdf available at https://authorea.com/users/382317/articles/498235-highvisceral-adiposity-index-associated-with-metabolic-syndrome-impairs-erectile-functionin-sexually-active-men 